Esta revista forma parte del acervo de la Biblioteca Jurídica Virtual del Instituto de Investigaciones Jurídicas de la UNAM

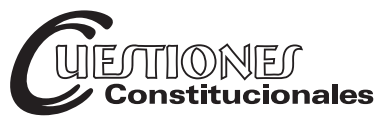

Revista Mexicana de Derecho Constitucional

Núm. 44, Enero-Junio 2021

ISSN (versión electrónica): 2448-4881

\title{
Crítica a la acción de inconstitucionalidad 113/2018 sobre el libre desarrollo de la personalidad en Jalisco
}

\author{
Criticism of the action of unconstitutionality 113/2018 \\ on the free development of personality in Jalisco
}

\author{
Jesús Francisco \\ RAMÍREZ BAÑUELOS*
}

\begin{abstract}
RESUMEN: Este es un análisis crítico sobre la resolución adoptada por la Suprema Corte de la Justicia de la Nación en la acción de inconstitucionalidad $113 / 2018$ en la que se declara la invalidez de la porción normativa del artículo 420 del Código Civil del Estado de Jalisco que condiciona a los excónyuges a esperar un año para contraer nuevas nupcias. Se analiza cómo la resolución constitucional protege el derecho fundamental al libre desarrollo de la personalidad y transforma la estructura jurídica local en materia de divorcio.
\end{abstract}

Palabras clave: libre desarrollo de la personalidad, divorcio, Código Civil del Estado de Jalisco.
ABSTRACT: This is a critical analysis of the resolution adopted by the Supreme Court of Justice of the Nation in the action of unconstitutionality 113/2018 in which it declares the invalidity of the normative portion of article 420 of the Civil Code of the State of Jalisco that conditions ex-spouses to wait a year to contract new marriages. It analyses how the constitutional resolution protects the fundamental right to the free development of personality and transforms the local legal structure in matters of divorce.

Keywords: free development of personality, divorce, Civil Code of the State of Jalisco.

* M2 en Historia del pensamiento jurídico contemporáneo por la Universidad Paris 1 Panthéon-Sorbonne. México. Correo electrónico: ramirezbanuelos@gmail.com ORCID: 0000-0002-7458-9853. 
Esta revista forma parte del acervo de la Biblioteca Jurídica Virtual del Instituto de Investigaciones Jurídicas de la UNAM

SUMARIO: I. Introducción. II. Antecedentes. III. La acción de inconstitucionalidad 113/2018. IV. Conclusiones. V. Bibliografia.

\section{INTRODUCCIÓN}

La reglamentación del divorcio en el estado de Jalisco se ha reconfigurado en el último quinquenio fundamentalmente con sustento en decisiones dictadas por la Suprema Corte de Justicia de la Nación. La primera decisión fue la jurisprudencia por contradicción de tesis referida a la inconstitucionalidad de la exigencia en las legislaciones locales de la acreditación de causales para decretar el divorcio necesario (Primera Sala, 2015: 570).

La segunda fue la tesis aislada en la que se hace referencia específicamente al artículo 404 del Código Civil del estado de Jalisco como violatorio al derecho fundamental al libre desarrollo de la personalidad, al exigir la acreditación de causales para decretar la disolución del vínculo matrimonial (Primera Sala, 2015b: 975).

Como resultado de esas decisiones, el Congreso del Estado de Jalisco publicó el 17 de noviembre de 2018 en el periódico oficial El Estado de Jalisco el Decreto 27057/LXI/18 que reformó, entre otros, los artículos 404 y 420 del Código Civil del Estado de Jalisco (Congreso del Estado de Jalisco, 2018).

La tercera decisión es la acción de inconstitucionalidad 113/2018 promovida por la Comisión Nacional de los Derechos Humanos, en la que se demanda la inconstitucionalidad precisamente del reformado artículo 420 del Código Civil de esa Entidad por considerarlo violatorio al derecho humano al libre desarrollo de la personalidad (Suprema Corte de Justicia de la Nación, 2020).

Este ensayo es un análisis crítico sobre la resolución adoptada por la Suprema Corte de la Justicia de la Nación en esa acción de inconstitucionalidad. Nos interesamos puntualmente en analizar cómo la resolución constitucional protege el derecho fundamental al libre desarrollo de la personalidad y transforma la estructura jurídica local en materia de divorcio.

Primeramente, destacamos los antecedentes de la reforma al artículo 420 del Código Civil jalisciense aprobada por el Congreso del Estado de Jalisco (II).

Posteriormente, analizamos los alcances de la resolución adoptada por el Pleno de la Suprema Corte de Justicia de la Nación en la acción de incons- 
Esta revista forma parte del acervo de la Biblioteca Jurídica Virtual del Instituto de Investigaciones Jurídicas de la UNAM

titucionalidad 113/2018, respecto al artículo 420 y, por extensión de efectos indirectos, al 393, ambos del Código Civil del Estado de Jalisco (III).

\section{ANTECEDENTES}

El Decreto 27057/LXI/1830 del Congreso del Estado de Jalisco de 17 de noviembre de 2018 es producto de dos iniciativas de reforma de ley, que a continuación veremos.

La primera, registrada como INFOLEJ300/LXI fue propuesta el 21 de enero de 2016 por el Diputado Ing. Salvador Arellano Guzmán (Congreso del Estado de Jalisco, 2018: 2-10). En lo sustancial esta iniciativa se sustenta en la existencia de la jurisprudencia citada anteriormente (Primera Sala, 2015a: 570) sobre la invalidez constitucional de la existencia de causales de divorcio en los códigos sustantivos locales que había implicado un cambio en la práctica en la tramitación de los juicios de divorcio en el Estado de Jalisco, puesto que tanto los postulantes como los jueces atendían directamente al criterio jurisprudencial e inaplicaban la legislación local.

Ante tal circunstancia el proyecto de reforma pretendió hacer compatible la reglamentación del divorcio en Jalisco con el criterio jurisprudencial de la Suprema Corte de Justicia de la Nación. Para ello, se propuso eliminar las causales de divorcio contencioso contempladas en el artículo 404 del Código Civil estatal para dejar como únicas razones para promover el divorcio el mutuo consentimiento y la solicitud unilateral de cualquiera de los cónyuges sin expresión de motivo. Es decir, se propuso eliminar el divorcio contencioso y las disposiciones que de él se derivaban.

Es en ese sentido que esta iniciativa de ley, al revisar el artículo 420 del Código Civil de Jalisco encontró que preveía un lapso posterior al divorcio contencioso de dos años para el cónyuge culpable y un año para el cónyuge inocente para que estuvieran en aptitud de contraer nuevas nupcias. Por ello, el legislador simplemente eliminó la porción normativa relativa al divorcio contencioso y mantuvo la restricción genérica de un año posterior a la disolución matrimonial para que las personas humanas puedan contraer un nuevo matrimonio.

La segunda iniciativa de ley, identificada como INFOLEJ4728/LXI fue presentada el 19 de octubre de 2017 por el Gobernador del Estado (Congreso del Estado de Jalisco, 2018: 11-61). Esta propuesta consideró las obligaciones del Estado en materia de derechos humanos derivadas de la Constitu- 
Esta revista forma parte del acervo de la Biblioteca Jurídica Virtual del Instituto de Investigaciones Jurídicas de la UNAM

ción federal, particularmente de la reforma al artículo 1o. de 11 de junio de 2011; la Constitución local; la Ley General para la Igualdad entre Mujeres y Hombres; la Ley General de Acceso de las Mujeres a una Vida Libre de Violencia federal y su correlativa estatal; y la Convención sobre la eliminación de todas las formas de discriminación contra la Mujer.

La iniciativa del Gobernador del Estado obedecía sustancialmente a la estrategiaJunt@s por ellas consistente en diversas acciones estatales que derivaron en la creación del Grupo Interinstitucional y Multidisciplinario para diagnosticar la situación de violencia de las mujeres en esa entidad federativa.

Producto de esos trabajos, diversas organizaciones de la sociedad civil solicitaron a la Secretaría de Gobernación la emisión de la Alerta de Género para el Estado de Jalisco. Dentro de las conclusiones del informe del grupo de trabajo, que solicitó la Alerta de Género, se propuso reformar, entre otros, los artículos 404 y 420 del Código Civil. El primero, para eliminar las causales de divorcio contencioso; y el segundo para eliminar las restricciones para que los divorciados pudieran volver a casarse una vez decretado el divorcio.

Por esas razones, el Gobernador del Estado adoptó los resultados de las mesas de trabajo y propuso la iniciativa de reforma para armonizar la legislación civil local con una perspectiva de género y enfoque de derechos humanos, en los términos que lo proponían las organizaciones de la sociedad civil. Esto es, se propuso eliminar las causales de divorcio y en su lugar establecer un procedimiento especial de divorcio incausado; distinguiéndolo únicamente en administrativo y judicial; y eliminar los plazos para contraer matrimonio una vez decretado el divorcio.

Cabe señalar que esta iniciativa de ley proponía derogar el artículo 408 del Código Civil estatal, el cual establece que en caso de que los cónyuges opten por el divorcio por mutuo consentimiento y se reconcilien antes de que se dicte sentencia, no podrán promover un nuevo juicio de divorcio por mutuo consentimiento, sino después de tres meses del último acuerdo judicial (Código Civil del Estado de Jalisco, 1995, artículo 408).

Una vez turnadas las iniciativas de ley INFOLEJ300/LXI e INFOLEJ 4728/LXI a la Comisión de Puntos Constitucionales, Estudios Legislativos y Reglamentos, se procedió a su estudio. El 16 de octubre de 2018 se emitió el Dictamen de decreto que aprueba diversas iniciativas que reforman el Código Civil y el Código de Procedimientos Civiles, ambos ordenamientos del Estado de Jalisco (Congreso del Estado de Jalisco, 2018: 62-102). Ese 
Esta revista forma parte del acervo de la Biblioteca Jurídica Virtual del Instituto de Investigaciones Jurídicas de la UNAM

dictamen, si bien es cierto que valoró ambas iniciativas, no menos cierto es que los motivos que adoptó para su emisión fueron reduccionistas y desvinculados de los enfoques de perspectiva de género y derechos humanos al concluir que ambas propuestas de ley establecen como fundamento la contradicción de tesis de la Suprema Corte de Justicia de la Nación respecto a la inconstitucionalidad de prever causales en los códigos locales para decretar el divorcio (Primera Sala, 2015a).

Por ello, el dictamen argumenta que el objetivo de las iniciativas es adicionar el divorcio por voluntad de uno de los cónyuges y eliminar las causales del divorcio contencioso.

Pero la Comisión dictaminadora fue omisa en pronunciarse respecto al resto de las proposiciones de la iniciativa INFOLEJ4728/LXI y adoptó la propuesta de iniciativa INFOLEJ300/LXI, la cual fue sometida al Congreso local y aprobada el 30 de octubre de 2018 con algunas modificaciones no sustanciales a nuestro propósito.

El decreto de reformas se publicó en el Periódico Oficial El Estado de Jalisco el 17 de noviembre de 2018 y entró en vigor al día siguiente de su publicación.

\section{LA ACCIÓN DE INCONSTITUCIONALIDAD 113/2018}

\section{La solicitud de acción de inconstitucionalidad}

El 17 de diciembre de 2018 la Comisión Nacional de los Derechos Humanos planteó ante la Suprema Corte de Justicia de la Nación la acción de inconstitucionalidad del artículo 420 del Código Civil del Estado de Jalisco.

La Comisión Nacional de los Derechos Humanos sostiene que la porción normativa del artículo 420 del Código Civil del Estado de Jalisco en lo que dice "... siendo indispensable que haya transcurrido un año desde que obtuvieron el divorcio" viola los artículos $1^{\circ}$ y $4^{\circ}$ de la Constitución Política de los Estados Unidos Mexicanos; así como los diversos $1^{\circ}, 2^{\circ}, 5^{\circ}, 11$ y 24 de la Convención Americana sobre Derechos Humanos; y los arábigos $3^{\circ}, 23$ y 26 del Pacto Internacional de Derechos Civiles y Políticos.

En lo particular, la Comisión Nacional de los Derechos Humanos considera que el artículo cuya inconstitucionalidad se impugna viola los dere-

1 Código Civil del Estado de Jalisco, (1995), artículo 420. 
Esta revista forma parte del acervo de la Biblioteca Jurídica Virtual del Instituto de Investigaciones Jurídicas de la UNAM

chos fundamentales de la integridad personal, el libre desarrollo de la personalidad y el derecho a contraer matrimonio; así como la obligación del Estado de promover, proteger, respetar y garantizar los derechos humanos. ${ }^{2}$ Ello en razón a que a su entender la codificación local condiciona ilegalmente los derechos fundamentales al libre desarrollo de la personalidad y a contraer matrimonio.

La Comisión Nacional de los Derechos Humanos recuerda que la jurisprudencia de nuestro más alto Tribunal ha establecido que el derecho fundamental a la dignidad humana se compone, entre otros, del derecho al libre desarrollo de la personalidad, el cual se expresa en la libre elección a contraer o no matrimonio. Por ello, el Estado no puede válidamente interferir en esas decisiones que son propias a la libertad de las personas humanas.

Asimismo, la Comisión Nacional de los Derechos Humanos pone en relevancia que el artículo 403 del Código Civil de Jalisco dispone que, en virtud del divorcio los excónyuges recuperan su derecho a contraer un matrimonio subsecuente. ${ }^{3}$ Sin embargo, esa previsión encuentra una limitante en el artículo 420 del mismo cuerpo legal que, como se ha señalado, impone una condición temporal para que ese derecho se pueda hacer valer por las personas humanas.

Además, la Comisión Nacional de Derechos Humanos considera que la norma cuya constitucionalidad se cuestiona implica un trato diferenciado entre las personas solteras que nunca han sido casadas y las que habiendo sido casadas optan por divorciarse; puesto que mientras las primeras pueden contraer matrimonio en cualquier momento, las segundas deben esperar un año después de decretado el divorcio.

\section{La sentencia del Tribunal Pleno de la Suprema}

\section{Corte de Justicia de la Nación}

La acción de inconstitucionalidad del artículo 420 del Código Civil del Estado de Jalisco promovida por la Comisión Nacional de los Derechos Humanos fue turnada a la Ponencia de la Ministra Piña Hernández, cuyo

2 Comisión Nacional de los Derechos Humanos (2018), Demanda de acción de inconstitucionalidad promovida por la Comisión Nacional de los Derechos Humanos en https://www.cndh.org.mx/sites/all/doc/Acciones/Acc_Inc_2018_LSI.pdf.

3 Código Civil del Estado de Jalisco, (1995), artículo 403.

Cuestiones Constitucionales, Núm. 44, Enero-Junio 2021

ISSN: $2448-4881$ 
Esta revista forma parte del acervo de la Biblioteca Jurídica Virtual del Instituto de Investigaciones Jurídicas de la UNAM

proyecto se discutió en la sesión ordinaria a distancia celebrada por el Tribunal Pleno el 18 de junio de $2020 .{ }^{4}$

En nuestra consideración, el proyecto de sentencia de la Ministra Piña Hernández analiza con cierta ligereza la acción de inconstitucionalidad planteada.

Ciertamente, el proyecto de resolución en su segundo punto resolutivo concluye acertadamente que la porción normativa del artículo 420 del Código Civil del Estado de Jalisco que dispone "... siendo indispensable que haya transcurrido un año desde que obtuvieron el divorcio" es contraria a la Constitución federal, al violentar el derecho al libre desarrollo de las personas y, por ende, se declara su inconstitucionalidad. Pero consideramos que los argumentos esgrimidos por la Ministra Ponente no son exhaustivos para comprender la trascendencia de la inconstitucionalidad decretada en el ordenamiento civil del Estado de Jalisco.

Al respecto, la Ministra Piña Hernández al exponer el capítulo del estudio de fondo de su proyecto ante el Pleno de la Corte señaló en primer término que de los documentos relativos al proceso legislativo no se advierte la motivación jurídica que llevó al legislador a justificar la porción normativa, cuya constitucionalidad se cuestiona.

Esa afirmación no corresponde a la realidad, toda vez que la iniciativa de ley INFOLEJ300/LXI, que resultó dictaminada favorablemente por la Comisión dictaminadora del Congreso local, planteó la necesidad de armonizar la reglamentación civil sustantiva de Jalisco con la jurisprudencia de la Suprema Corte de Justicia de la Nación, en el sentido de que es inconstitucional mantener en las codificaciones estatales las causales como razones jurídicas para que proceda el divorcio.

Luego, la reforma toral del Decreto 27057/LXI/1830 que se publicó en el Periódico Oficial El Estado de Jalisco el 17 de noviembre de 2018 fue la de eliminar el divorcio contencioso, lo que en el caso del Estado de Jalisco se fundamentaba en el artículo 404 del Código Civil. A partir de ese eje, el legislador modificó y derogó total o parcialmente los artículos de ese cuerpo normativo necesarios para armonizarlos con la eliminación del divorcio contencioso.

4 Suprema Corte de Justicia de la Nación, (2020), Contenido de la versión taquigráfica de la Sesión Pública Ordinaria del Pleno de la Suprema Corte de Justicia de la Nación celebrada a distancia el jueves 18 de junio de 2020, https://www.scjn.gob.mx/si tes/default/files/versiones-taquigraficas/documento/2020-06-18/18\%20de\%20junio\%20 de\%202020\%20-\%20Versi\%C3\%B3n\%20definitiva.pdf. 
Esta revista forma parte del acervo de la Biblioteca Jurídica Virtual del Instituto de Investigaciones Jurídicas de la UNAM

Es en ese sentido que al legislador local se le puede reprochar que con una técnica legislativa deficiente y sin observar la perspectiva de género ni de derechos humanos se limitó en el caso del artículo 420 del Código Civil a derogar parcialmente las limitaciones temporales que estaban establecidas por la norma para que los ex cónyuges que hubieran obtenido su divorcio en un procedimiento contencioso no pudieran contraer nuevas nupcias en dos y un año, según se tratase del cónyuge culpable o inocente, respectivamente.

Pero, contrario a lo que manifiesta la Ministra Ponente, el legislador sí tuvo un motivo para mantener la limitación -que evidentemente viola el desarrollo a la libre determinación de las personas- para contraer nuevas nupcias. Ese motivo fue que la reforma del artículo 404 y por vía de consecuencia, entre otros, del artículo 420 ambos del Código Civil local atendía únicamente a la eliminación del divorcio necesario para armonizarlo con la jurisprudencia del Máximo Tribunal, en materia de las causales del divorcio necesario.

De ahí que la razón jurídica para la existencia de la condición de que los excónyuges que obtuvieron el divorcio contencioso deban esperar un año para volver a casarse no se deba buscar en la exposición de motivos del legislador reformador actual, sino en el origen de la norma.

A este respecto, la Ministra Ponente afirma que la limitación temporal para contraer nuevas nupcias se debe a la protección de la familia anterior o la futura; o bien como una sanción para los excónyuges. Sin embargo, nos apartamos de esa consideración y estimamos que la restricción legal que preveía el lapso de un año para que los divorciados pudieran volver a casarse tenía su razón jurídica en la presunción iuris tantum contemplada en el artículo 456 fracción II del mismo Código Civil referente a que los hijos nacidos dentro de los trescientos días (aproximadamente diez meses) siguientes a la disolución del vínculo matrimonial se presumen hijos del matrimonio. $^{5}$

En este sentido, echamos en falta que la Ministra Ponente no haya hecho referencia a esa presunción legal, aunque sea para referir que la eliminación de la condición temporal prevista en el artículo 420 del Código Civil no incide directamente en el artículo 456 fracción II a que hacemos referencia.

Por otra parte, yerra la Ministra Ponente al señalar que la iniciativa de reforma no contenía la restricción temporal de un año para que los excón-

5 Código Civil del Estado de Jalisco, (1995), artículo 456 fracción II.

Cuestiones Constitucionales, Núm. 44, Enero-Junio 2021

ISSN: 2448-4881 
Esta revista forma parte del acervo de la Biblioteca Jurídica Virtual del Instituto de Investigaciones Jurídicas de la UNAM

yuges puedan volver a contraer nupcias. Lo anterior, dado que la iniciativa INFOLEJ300/LXI ${ }^{6}$ sí contenía esa limitante en el texto del artículo 420 del código sustantivo civil, siendo la iniciativa INFOLEJ4728/LXI ${ }^{7}$ la que no contenía esa restricción.

También llama la atención que la Ministra Ponente no se haya referido a la iniciativa de ley INFOLEJ4728/LXI, que, aunque no fue adoptada por la Comisión dictaminadora sí forma parte del dictamen de esa Comisión. Lo anterior, sobre todo, dado que esa iniciativa se corresponde con los criterios jurisprudenciales de la Suprema Corte de Justicia de la Nación en materia de divorcio incausado.

Por otra parte, destacamos que el proyecto de resolución de la Ponente haya pasado por alto los efectos indirectos de la inconstitucionalidad decretada. En ese sentido, fue la Ministra Esquivel Mossa quien acertadamente llamó la atención del Tribunal Pleno en cuanto a la extensión de los efectos indirectos de la inconstitucionalidad del artículo 420 del Código Civil del Estado de Jalisco al diverso 393 del mismo ordenamiento legal y que se refiere a los casos de ilicitud del matrimonio.

En el particular, el artículo 393 del Código Civil del Estado de Jalisco señala que un matrimonio es ilícito si no se respeta el lapso previsto en el artículo 420 de la misma codificación civil. ${ }^{8}$ Esto es, la Ministra Ponente omitió estudiar la extensión de los efectos indirectos de la declaración de inconstitucionalidad decretada, aunque en el caso de la disposición del 393 pareciera no ser de trascendencia, dado que de no haberse advertido su vinculación con el arábigo 420, la remisión del primero de los artículos al segundo habría encontrado un vacío y no tendría efectos.

Por otra parte, se destaca también la omisión del proyecto en cuanto ve al estudio de la posible extensión de efectos indirectos de la declaración de inconstitucionalidad al artículo 408 del Código Civil del Estado de Jalisco. Ello en razón a que ese dispositivo referido al divorcio por mutuo consentimiento prevé que en caso de haber una reconciliación entre los cónyuges antes de que se dicte sentencia, estos no podrán volver a solicitar un juicio

6 Congreso del Estado de Jalisco, (2018), Decreto 27057/LXI/1830, disponible en: https://congresoweb.congresojal.gob.mx/Servicios/sistemas/SIP/decretossip/decretos/ Decretos\%20LXI/Decreto\%2027057.pdf.

7 Congreso del Estado de Jalisco, (2018), Decreto 27057/LXI/1830, disponible en: https://congresoweb.congresojal.gob.mx/Servicios/sistemas/SIP/decretossip/decretos/ Decretos\%20LXI/Decreto\%2027057.pdf.

8 Código Civil del Estado de Jalisco, (1995), artículo 393. 
Esta revista forma parte del acervo de la Biblioteca Jurídica Virtual del Instituto de Investigaciones Jurídicas de la UNAM

por mutuo consentimiento, sino hasta pasados tres meses de la última actuación judicial. ${ }^{9}$

Es decir, el estado actual del Código Civil de Jalisco realiza un trato diferenciado entre las personas que habiendo optado por divorciarse por mutuo consentimiento y las que lo hacen por la solicitud unilateral sin expresión de motivo logran reconciliarse temporalmente y deciden posteriormente intentar una nueva acción de divorcio.

Esto es así, toda vez que en el caso de las personas que deciden divorciarse por mutuo consentimiento se impone una condición temporal de tres meses para el caso de que, habiéndose reconciliado, decidan finalmente divorciarse; lo que no ocurre para el caso de las personas que hayan decidido divorciarse por solicitud unilateral y que en el transcurso del proceso se reconcilien y posteriormente reiteren su deseo de divorciarse.

Cabe señalar que esa disposición condiciona directamente la eficacia del artículo 420 del Código Civil del Estado de Jalisco, ya que en el caso de las personas reconciliadas en un divorcio por mutuo consentimiento no pueden contraer matrimonio sin antes estar divorciadas y para solicitar el divorcio deben esperar tres meses para promoverlo nuevamente por mutuo consentimiento. Es decir, las personas humanas en este caso particular no pueden ejercer libremente su derecho al libre desarrollo de la personalidad para elegir si permanecen o no casadas o quieren contraer un matrimonio subsecuente.

Finalmente, destacamos la situación anómala que se crea en el Código Civil del Estado de Jalisco con la declaración de inconstitucionalidad parcial del artículo 420, al subsistir dos preceptos jurídicos casi idénticos, que regulan el mismo supuesto legal; a saber, el artículo 403 que señala "El divorcio disuelve el vínculo matrimonial y deja a los que fueron cónyuges en aptitud de contraer otro" y el impugnado 420, que establece "En virtud del divorcio, los cónyuges recobrarán su entera capacidad para contraer nuevo matrimonio".

Consideramos que la declaración de inconstitucionalidad del artículo 420 del Código Civil del Estado de Jalisco debió ser total y no únicamente sobre la porción "... siendo indispensable que haya transcurrido un año desde que obtuvieron el divorcio". Lo anterior, a fin de dar coherencia al sistema jurídico planteado en el Código Civil jalisciense.

\footnotetext{
9 Código Civil del Estado de Jalisco, (1995), artículo 408.
}

Cuestiones Constitucionales, Núm. 44, Enero-Junio 2021

ISSN: 2448-4881 
Esta revista forma parte del acervo de la Biblioteca Jurídica Virtual del Instituto de Investigaciones Jurídicas de la UNAM

\section{CONCLUSIONES}

La acción de inconstitucionalidad 113/2018 decreta correctamente la invalidez constitucional del artículo 420 del Código Civil del Estado de Jalisco en su porción normativa que establece una condición temporal de un año para que los cónyuges divorciados puedan volver a casarse.

No obstante, la motivación de la resolución constitucional no es exhaustiva. Se dice que no es exhaustiva, dado que no estudia adecuadamente los efectos indirectos de la declaración de inconstitucionalidad del artículo 420 del Código Civil jalisciense en el sistema jurídico normativo de ese ordenamiento. Esto es así, ya que a pesar de que el Tribunal Pleno salva la omisión de la Ponente en cuanto ve a extender los efectos indirectos de la declaración de inconstitucionalidad al artículo 393 del código sustantivo civil local; no sucede lo mismo respecto al diverso 408 del mismo ordenamiento.

El subsistente artículo 408 del Código Civil de Jalisco realiza un trato diferenciado para las personas humanas que opten por divorciarse por mutuo consentimiento. En particular, el dispositivo en comento sanciona a los cónyuges que decidan divorciarse por mutuo consentimiento y durante el trámite se reconcilien, puesto que los condiciona que no puedan volver a solicitar el divorcio por mutuo consentimiento sino después de pasados tres meses del último acuerdo judicial.

Tal condicionante afecta directamente el derecho al libre desarrollo de la personalidad de las personas humanas para elegir si están casadas o solteras que fue objeto de protección de la acción de inconstitucionalidad $113 / 2018$.

De manera que el medio de control constitucional no fue en este caso suficientemente útil para proteger el derecho fundamental de las personas a decidir libremente si quieren o no estar casadas.

Por último, dejamos apuntado que como consecuencia de la resolución de inconstitucionalidad pronunciada por el Tribunal Pleno se ocasiona una irregularidad jurídica en el Código Civil del estado de Jalisco, en razón a que subsisten dos normas jurídicas de igual jerarquía contenidas inclusive dentro del mismo capítulo y que regulan el mismo supuesto legal. Nos referimos a los artículos 403 y 420 ambos del Código Civil del Estado de Jalisco.

\section{BIBLIOGRAFÍA}

Código Civil del Estado de Jalisco (1995). 
Esta revista forma parte del acervo de la Biblioteca Jurídica Virtual del Instituto de Investigaciones Jurídicas de la UNAM

Comisión Nacional de los Derechos Humanos. (2018), Demanda de acción de inconstitucionalidad promovida por la Comisión Nacional de los Derechos Humanos, disponible en: https://www.cndh.org.mx/sites/all/doc/ Acciones/Acc_Inc_2018_LSI.pdf.

Congreso del Estado de Jalisco. (2018). Decreto 27057/LXI/1830, disponible en: https://congresoweb.congresojal.gob.mx/Servicios/sistemas/SIP/ decretossip/decretos/Decretos\%20LXI/Decreto\%2027057.pdf.

Suprema Corte de Justicia de la Nación. (2020) Contenido de la versión taquigráfica de la Sesión Pública Ordinaria del Pleno de la Suprema Corte de Justicia de la Nación celebrada a distancia el jueves 18 de junio de 2020, disponible en: https://www.scjn.gob.mx/sites/default/files/versio nes-taquigraficas/documento/2020-06-18/18\%20de\%20junio\%20de\% 202020\%20-\%20Versi\%C3\%B3n\%20definitiva.pdf.

Suprema Corte de Justicia de la Nación. Primera Sala. (2015a). Tesis 1a./J.28/2015. Semanario Judicial de la Federación y su Gaceta. Décima Época. Tomo I, p. 570.

Suprema Corte de Justicia de la Nación. Primera Sala. (2015b). Tesis 1a. CCCLXV/2015. Semanario Judicial de la Federación y su Gaceta, Décima Época. Tomo I. 